\title{
Microwave-Assisted Tissue Preparation for Rapid Fixation, Decalcification, Antigen Retrieval, Cryosectioning, and Immunostaining
}

\author{
Kazuo Katoh \\ Laboratory of Human Anatomy and Cell Biology, Faculty of Health Sciences, Tsukuba University of Technology, \\ 4-12-7 Kasuga, Tsukuba, Ibaraki 305-8521, Japan \\ Correspondence should be addressed to Kazuo Katoh; katoichi@k.tsukuba-tech.ac.jp
}

Received 30 August 2016; Accepted 3 October 2016

Academic Editor: Richard Tucker

Copyright (C) 2016 Kazuo Katoh. This is an open access article distributed under the Creative Commons Attribution License, which permits unrestricted use, distribution, and reproduction in any medium, provided the original work is properly cited.

\begin{abstract}
Microwave irradiation of tissue during fixation and subsequent histochemical staining procedures significantly reduces the time required for incubation in fixation and staining solutions. Minimizing the incubation time in fixative reduces disruption of tissue morphology, and reducing the incubation time in staining solution or antibody solution decreases nonspecific labeling. Reduction of incubation time in staining solution also decreases the level of background noise. Microwave-assisted tissue preparation is applicable for tissue fixation, decalcification of bone tissues, treatment of adipose tissues, antigen retrieval, and other special staining of tissues. Microwave-assisted tissue fixation and staining are useful tools for histological analyses. This review describes the protocols using microwave irradiation for several essential procedures in histochemical studies, and these techniques are applicable to other protocols for tissue fixation and immunostaining in the field of cell biology.
\end{abstract}

\section{Introduction}

Microwave irradiation during tissue processing markedly reduces the time required for fixation, decalcification, staining with chemical reagents, and incubation with antibodies.

Since the mid-1980s, microwave irradiation has been increasingly used in histological preparation. Microwave irradiation induces rapid oscillation of water molecules $(2.45 \mathrm{GHz})$ and thus increases tissue temperature. Conventional microwave devices irradiate tissues both rapidly and uniformly, and microwave irradiation protocols differ according to the specific microwave devices used.

Microwave irradiation is routinely applied for special staining [1-12]. Microwave irradiation has also been applied during fixation [13] and subsequent staining procedures, such as enzyme-based staining and immunofluorescence staining.

During preparation of tissues for immunohistological studies, many artifacts that disrupt the original signals may occur, most of which are commonly associated with late fixation or low fixative volume. Late preparation of tissues causes decomposition of proteins, resulting in a lack of certain epitopes. Disruption of proteins during fixation adversely affects the epitope-antibody reaction during immunohistochemistry. Moreover, morphological changes also occur during fixation of cryosections and/or samples for electron microscopy. Conventional fixation may also result in shrinkage of tissues, such as skeletal or smooth muscle cells, or of cultured cells due to insufficient penetration of fixative (e.g., formalin solution) to completely fix tissues, and a long time is needed for fixation.

Microwave irradiation can be used to achieve more rapid fixation, solution processing, and immunostaining [13-38]. Microwave irradiation is also applied for fluorescence in situ hybridization (FISH) analysis of paraffin-embedded tissues [39-41]. Recently, the author described microwave-irradiated blood vessel fixation and immunofluorescence microscopy [42]. In this case, microwave irradiation was used to increase penetration of fixatives. The use of microwave irradiation also reduced nonspecific binding of fluorescently labeled antibodies when fixed samples were immunostained. Rapid tissue fixation and immunofluorescence staining of cultured cells using microwave irradiation have also been described [43]. 
Microwave irradiation was shown to significantly reduce the required incubation times with primary and secondary antibodies in immunofluorescence microscopy. We utilized a technique involving exposure of cultured cells to intermittent microwave irradiation during fixation, which resulted in good preservation of tissue immunoreactivity compared with conventional fixation, along with reduced fixation time [43].

Another issue affecting histological analysis is the effect of pretreating hard tissues, such as bone, which requires decalcification after fixation to soften the tissue and allow it to be cut using a microtome. A long time is also required to remove fat from some tissues. Conventional decalcification requires a period of about 1-2 weeks, which prevents early diagnosis in histological research $[44,45]$. Tissue preparation for electron microscopy, which involves fixation and subsequent solution treatment, is also problematic. Fixation using formalin-based fixatives causes tissue shrinkage. Solution treatment, such as dehydration by passage through an alcohol series, requires a relatively long time in conventional protocols.

Conventional antigen retrieval was generally performed using an autoclave chamber at high temperature $\left(\sim 121^{\circ}\right)$ and high pressure and always caused tissue disruption and removal from the slides. Microwave irradiation is also highly applicable for antigen retrieval on paraffin-embedded tissue sections [46-49].

Microwave tissue processing markedly reduces the processing time required for enzyme reaction, peroxidase processing, and blocking procedures. Microwave irradiation reduces the processing time to $1 / 3-1 / 10$ compared to that of conventional procedures. Moreover, microwave irradiation yields low-background, high-contrast images due to the reduced nonspecific binding of staining solution or antibodies for immunofluorescence staining.

Several microwaves that allow user-selectable control of irradiation power from 150 to $400 \mathrm{~W}$ are available. It is also possible to precisely control the temperature using two independent systems, for example, infrared and thermocouple temperature measurement systems.

This review describes a microwave-assisted tissue preparation protocol for tissue fixation, decalcification of bone tissue, fixation of fatty (adipose) tissues, antigen retrieval of paraffin-embedded tissues, and other techniques for which microwave irradiation is applicable. In addition, application of microwave irradiation for electron microscopy of blood vessel cells in situ is also discussed.

\section{Application for Tissue Fixation}

2.1. Fixation of Blood Vessels In Situ [42, 50]. Due to the difficulties associated with fixation of blood vessels, because of the shrinkage of smooth muscle tissues, there have been only a few studies using blood vessels in situ. It is very difficult to obtain good fixation of blood vessels in animals, especially endothelial cells, compared to those obtained from other organs. Perfusion of paraformaldehyde causes smooth muscle contraction according to the penetration of formalinbased fixatives. During fixation, blood vessels shrink rapidly during perfusion of paraformaldehyde solution. However, we have used microwave irradiation during fixation of blood vessels and achieved good preservation of both tissue morphology and immunoreactivity.

2.2. Protocol. Aortae are obtained from normal adult guinea pigs $400-600 \mathrm{~g}$ in body weight.

(1) Perfusion with $0.85 \% \mathrm{NaCl}$ containing heparin sodium $(1 \mathrm{U} / \mathrm{mL})$ is performed via the left ventricle, and the descending thoracic aorta, abdominal aorta, and inferior vena cava are excised.

(2) Vessels are cut open along the dorsal wall and pinned onto a dental wax plate, exposing the luminal surface.

(3) For light microscopy, the aorta is placed in a $100-\mathrm{mL}$ beaker containing $50 \mathrm{~mL}$ of $2 \%$ paraformaldehyde in phosphate-buffered saline (PBS).

For both scanning and electron microscopy, it is recommended to use 1/2 Karnovsky's fixative (2.5\% glutaraldehyde and $2 \%$ paraformaldehyde in $0.1 \mathrm{M}$ sodium cacodylate buffer, $\mathrm{pH}$ 7.2).

(4) The beaker is placed on the turntable of a microwave oven and subjected to intermittent microwave irradiation at $200 \mathrm{~W}$ for 5 minutes ( $4 \mathrm{~s} \mathrm{on} / 3 \mathrm{~s} \mathrm{off}$ ).

After microwave irradiation, the blood vessels are rinsed with two or three changes of PBS for 10 minutes each time without microwave irradiation. They are then cut crosswise into small segments (about 5-10 $\mathrm{mm}$ in length) and processed for either paraffin embedding or immunofluorescence microscopy (see Application for Immunofluorescence Microscopy).

\section{Fixation of Cultured Cells [43]}

Microwave irradiation is applicable for fixation of cultured cells. Conventional fixation of cultured cells requires at least $30-60$ minutes with $1 \%$ paraformaldehyde. Microwave irradiation during fixation significantly reduces the times required for both fixation and staining for immunofluorescence microscopy. All procedures, including fixation and antibody staining, are completed within 30-45 minutes without any loss of cell morphology and without nonspecific binding of dyes.

\subsection{Protocol}

(1) Cells are cultured on coverslips according to standard procedures.

(2) Cells are washed quickly with three changes of PBS.

(3) Cells are fixed with $1 \%$ paraformaldehyde with intermittent microwave irradiation (total 5 minutes; $4 \mathrm{~s}$ $\mathrm{on} / 3 \mathrm{~s}$ off at $200 \mathrm{~W}$ ).

(4) Fixed cells are quickly rinsed three times in PBS for a total of 5 minutes without microwave irradiation followed by immunofluorescence microscopy (see Application for Immunofluorescence Microscopy). 
3.2. Notes. Two coverslips $(18 \times 18 \mathrm{~mm})$ are placed in plastic culture dishes $50 \mathrm{~mm}$ in diameter. About $4 \mathrm{~mL}$ of fixative is added to the culture dish.

If using culture dishes $100 \mathrm{~mm}$ in diameter, more than 10 coverslips $(18 \times 18 \mathrm{~mm})$ can be fixed with $10 \mathrm{~mL}$ of fixative.

For microwave irradiation, the authors' laboratory uses a MI-77 type microwave irradiation device (Azumaya, Tokyo, Japan) with controllable microwave irradiation power and temperature control.

\section{Application for Decalcification $[26,27,33,44,45]$}

Decalcification is essential after bone fixation to obtain good paraffin sections. Decalcification of bone tissues for histological research requires a very long time, that is, 2-4 days with $10 \%$ formic acid or 1-2 weeks with $10 \%$ EDTA.

With microwave irradiation, however, the processing time can be reduced to $1 / 5-1 / 10$ of the original preparation time.

4.1. Decalcification Solution. $10 \%$ formic acid in distilled water or $10 \%$ neutral EDTA.

\subsection{Comments}

Formic Acid Decalcification

(1) For all procedures, use intermittent microwave irradiation at $400 \mathrm{~W}$ ( $5 \mathrm{~s}$ on $/ 5 \mathrm{~s}$ off $)$.

(2) Preparation time is reduced to $1 / 10$ of the original procedure. For formic acid, irradiation can be performed overnight.

(3) The formic acid solution temperature should not exceed $45^{\circ} \mathrm{C}$.

\section{EDTA Decalcification}

(1) Use intermittent microwave irradiation at $400 \mathrm{~W}(5 \mathrm{~s}$ on/5 s off).

(2) Preparation time is reduced to $1 / 10$ of the original procedure. For EDTA decalcification, irradiation can be performed for 2 or 3 days.

(3) The EDTA solution temperature should not exceed $45^{\circ} \mathrm{C}$.

(4) Decalcification solution should be changed every day.

Procedure time should be determined by each researcher. Processing time should be modified according to the size and hardness of bones. For microwave irradiation, the authors' laboratory uses a MI-77 type microwave irradiation device (Azumaya, Tokyo, Japan) with controllable microwave irradiation power and temperature control.

\section{Application for Immunohistochemistry $[7,17,21,27,33,36,38,51-53]$}

For immunohistochemistry experiments, avidin-biotin complex interaction (the ABC method) is generally used for detection of certain types of proteins using specific primary antibodies (Vectastain ABC Kit; Vector Laboratories, Burlingame, CA). Although it is a well-established procedure for histochemical investigations, conventional protocols for ABC method require 2-3 hours. Microwave irradiation reduces both the procedure time and background noise [51].

Deparaffinization should be performed according to standard methods. After deparaffinization, microwave irradiation can be applied. A protocol for immunohistochemistry using the $\mathrm{ABC}$ complex is presented below.

\subsection{Protocol}

(1) Deparaffinize tissues using standard procedures without microwave treatment.

(2) $\mathrm{H}_{2} \mathrm{O}_{2}$ treatment is performed to block endogenous peroxidase for 5 minutes with microwave treatment (intermittent irradiation; $5 \mathrm{~s}$ on $/ 5 \mathrm{~s}$ off at $200 \mathrm{~W}$ ).

(3) Antigen retrieval should be performed in this step (see Application for Antigen Retrieval of ParaffinEmbedded Samples).

(4) Wash briefly with PBS.

(5) Block with blocking solution for 5 minutes with microwave treatment ( $5 \mathrm{~s}$ on $/ 5 \mathrm{~s}$ off at $200 \mathrm{~W})$.

(6) Incubate with 1st antibody for 5 minutes with microwave treatment $(5 \mathrm{~s}$ on $/ 5 \mathrm{~s}$ off at $200 \mathrm{~W})$.

(7) Wash samples briefly with PBS for $10 \mathrm{~s}-1$ minute without microwave treatment.

(8) Incubate with biotinylated anti-mouse or anti-rabbit IgG with microwave treatment. (Secondary antibody varies according to the origin of the 1st antibody.)

(9) Wash samples briefly with PBS for 1 minute without microwave treatment.

(10) Incubate in Vectastain ABC solution for 3-5 minutes with microwave treatment ( $5 \mathrm{~s}$ on $/ 5 \mathrm{~s}$ off at $200 \mathrm{~W})$.

(11) Wash samples briefly with PBS twice for 1 minute each time without microwave treatment.

(12) Development of ABC complex with diaminobenzidine until staining develops without microwave treatment.

All reagents should be prepared according to the manual supplied with the Vectastain ABC Kit.

\section{Application for Immunofluorescence Microscopy $[35,37,42,50,54]$}

For immunofluorescence microscopy, microwave irradiation reduces incubation time to about $1 / 5-1 / 10$ of the original time. Our laboratory protocol for staining of guinea pig aorta and vena cava is presented below. This is an example of immunofluorescence staining of blood vessels. The following protocol should be applicable for other tissues, although the exact irradiation power and time of microwave treatment should be determined by each researcher. The detailed cultured cell protocol was reported previously [43]. 
For fixation using microwave irradiation (see also Application for Tissue Fixation), aortae are rinsed several times with PBS and cut into small pieces, and en face preparations are made.

\subsection{Protocol}

(1) Permeabilize the tissue with $0.5 \%$ Triton X-100 in PBS for 5 minutes without microwave irradiation.

(2) The specimens are then incubated with $10 \%$ normal goat serum for 5 minutes with intermittent microwave irradiation ( $4 \mathrm{~s}$ on $/ 3 \mathrm{~s}$ off at $200 \mathrm{~W})$.

(3) The specimens are rinsed several times with PBS without microwave irradiation.

(4) Incubation should then be performed with one of the primary antibodies (in this case, antipaxillin as a marker of adhesion plaques located at sites of cellsubstrate adhesion) for 5 minutes with intermittent microwave irradiation ( $4 \mathrm{~s} \mathrm{on} / 3 \mathrm{~s}$ off at $200 \mathrm{~W}$ ).

(5) Rinse specimens with PBS several times without microwave treatment.

(6) Incubate with FITC-labeled secondary antibody for 5 minutes with microwave irradiation $(4 \mathrm{~s}$ on $/ 3 \mathrm{~s}$ off at $200 \mathrm{~W})$.

(7) [Optional] Further staining with dyes can be performed, such as rhodamine-labeled phalloidin for Factin or propidium iodide for nuclear staining with microwave irradiation ( $4 \mathrm{~s} \mathrm{on} / 3 \mathrm{~s}$ off at $200 \mathrm{~W}$ ).

(8) Mount samples on slide glasses, followed by immunofluorescence or confocal laser scanning microscopy.

The temperature of samples should not exceed $40^{\circ} \mathrm{C}$ for immunofluorescence microscopy.

An example of typical double staining with antiphosphotyrosine (PY-20) antibody (BD Biosciences, Franklin Lakes, NJ) as a tyrosine-phosphorylated protein marker and rhodamine-labeled phalloidin for actin filament staining is shown in Figure 1. The above protocol is applicable for staining of cryosections (see also [42]). See also immunofluorescence microscopy of paraffin-embedded samples by other authors $[35,37]$.

\section{Application for Antigen Retrieval of Paraffin-Embedded Samples $[23,37,46-49]$}

In general, paraffin-embedded samples that have been fixed with paraformaldehyde are not suitable for immunohistochemical staining or in situ hybridization due to the masking of antigenic sites by protein-protein cross-linking with paraformaldehyde. In some formalin-fixed samples, antigens of certain proteins are masked according to protein crosslinking by formaldehyde. Therefore, formalin-fixed samples require antigen retrieval using special treatment. Heatinduced antigen retrieval is often used to retrieve the epitopes of proteins by autoclaving or using a commercially available pressure cooker. Heat-induced antigen retrieval sometimes causes damage to fixed samples.

Conventional procedures involved using an autoclave $\left(121^{\circ} \mathrm{C}\right.$ with pressure). In some cases, a household kitchen microwave oven (nearly $100^{\circ} \mathrm{C}$ ) was used. In many cases, tissues on slide glasses became detached, and high levels of background noise were observed because of tissue damage by high temperature.

Microwave irradiation using a purpose-built apparatus can yield stable experimental results for research $[46,49]$.

\subsection{Comments}

(1) Beaker with antigen retrieval solution $400 \mathrm{~mL}$ (e.g., Target Retrieval solution; DAKO, Produktionsvej, Denmark).

(2) Maximum solution temperature: $70^{\circ} \mathrm{C}-99^{\circ} \mathrm{C}$.

(3) Continuous irradiation for 20-30 minutes (intermittent irradiation: $5 \mathrm{~s}$ on $/ 5 \mathrm{~s}$ off at $400 \mathrm{~W})$.

(4) Precise reaction time determined by each researcher.

\section{Application for Processing Fatty Tissues}

Thymus gland, breast, and lymph node specimens are typical fatty (adipose) tissues. Fixation of fatty tissues is difficult because of the low penetration of paraformaldehyde solutions. Poor tissue fixation causes tissue destruction and "bubbles" in paraffin-embedded sections. Due to the poor penetration of paraformaldehyde solution, fatty tissues require treatment with a mixture of xylene and methanol after fixation. In general, treatment of fatty tissues requires about 1030 hours. With microwave irradiation, however, the fixation time can be significantly reduced to about $1 / 20-1 / 30$ with good fixation.

\subsection{Procedure. Take thymus gland as an example.}

Refer to Application for Tissue Fixation for tissue fixation protocol.

(1) Incubate fixed fatty tissues in beaker with treatment solution: xylene : methanol $=1: 1(500 \mathrm{~mL})$.

(2) Intermittent microwave irradiation for 30-60 minutes at $400 \mathrm{~W}$ ( $5 \mathrm{~s}$ on $/ 5 \mathrm{~s}$ off $)$ : replace treatment solution if there is sedimentation of fat.

(3) During microwave irradiation, the temperature should not exceed $50^{\circ} \mathrm{C}$.

Irradiation times should change according to the volume of the fatty tissues. Total irradiation time should be determined by each researcher.

\section{Other Applications of Microwave Irradiation}

9.1. Application for Electron Microscopy. Tissues to be analyzed by electron microscopy are usually embedded in resin for ultramicrotomy. Although the embedding procedures 


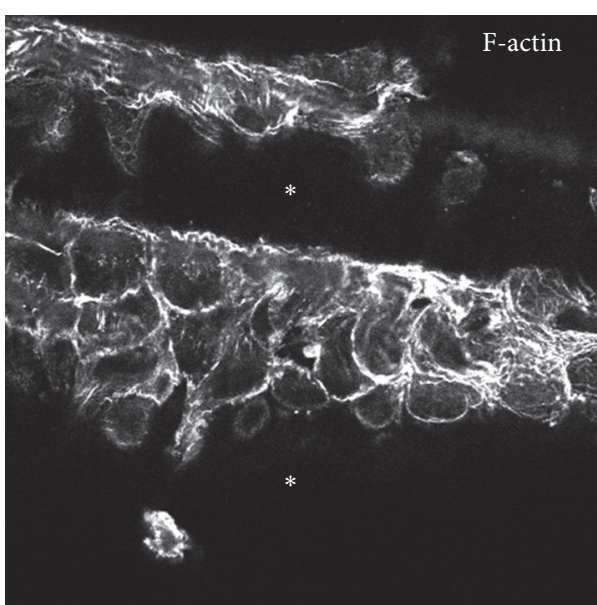

(a)

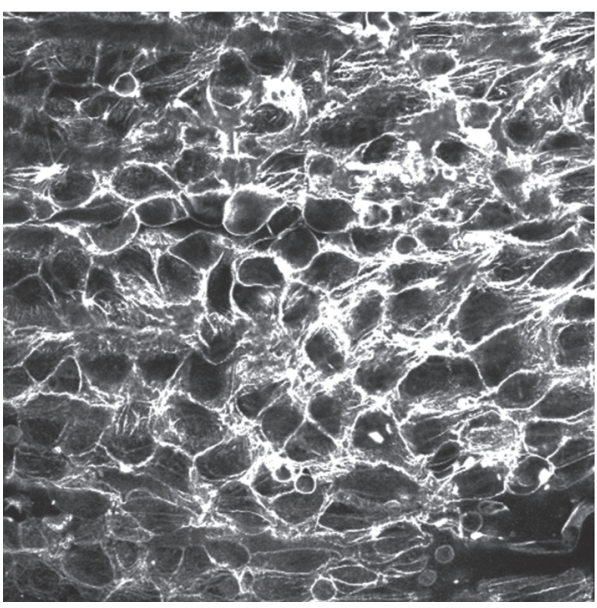

(c)

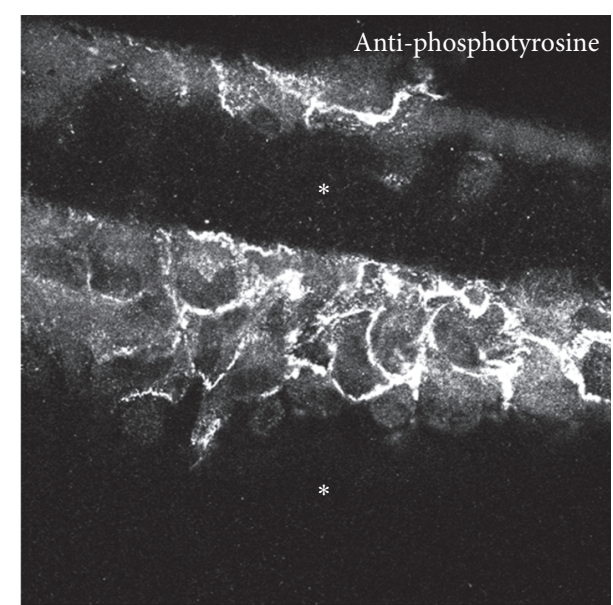

(b)

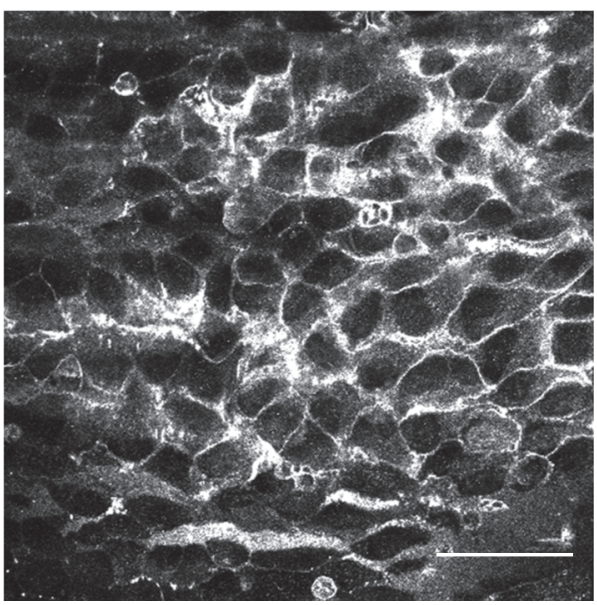

(d)

Figure 1: Comparison between conventional fixation ( $a$ and $b$ ) and microwave irradiation ( $c$ and $d$ ) of guinea pig aortic endothelial cells in whole-mount preparations. Conventionally fixed specimens showed shrinkage in the smooth muscle cell layer. Asterisks in (a) and (b) indicate gutters caused by shrinkage of the smooth muscle cell layer. Fixation with microwave irradiation showed well-preserved and flattened morphology of the endothelium ( $\mathrm{c}$ and d). Samples were stained with both anti-phosphotyrosine antibody to reveal tyrosine-phosphorylated proteins (b and d) and rhodamine-labeled phalloidin for F-actin staining (a and c). Samples were observed by confocal laser scanning microscopy, and focus was adjusted at the endothelial cell layer. Bar $=10 \mu \mathrm{m}$. See also [42].

vary with respect to chemical composition, they generally require about 1 week for processing. During sample preparation for electron microscopy, use of microwave irradiation reduces the procedure time to only 2 days without any loss of fine structure in tissue samples. Our microwave irradiation technique for fixation seems to be applicable to both transmission and scanning electron microscopy (see Figure 2 for SEM image).

Refer to Application for Tissue Fixation for tissue fixation protocol.

\subsection{Protocols}

(1) Postfixation with $1 \%$ osmium tetroxide in distilled water with microwave treatment for 15 minutes* (all procedures in this protocol use intermittent irradiation, $5 \mathrm{~s}$ on $/ 5 \mathrm{~s}$ off at $200 \mathrm{~W}$ ).
(1\% uranyl acetate incubation for 10 minutes with intermittent microwave irradiation if required.)

(2) Alcohol 50\% with microwave irradiation for $5 \mathrm{~min}$ utes.

(3) Alcohol 75\% with microwave irradiation for 5 minutes.

(4) Alcohol 90\% with microwave irradiation for 5 minutes.

(5) Alcohol 100\% with microwave irradiation for 5 minutes $\times 2$ times.

(6) Propylene oxide $100 \%$ with microwave irradiation for 5 minutes $\times 2$ times.

For Transmission Electron Microscopy $[56,57]$

(7) Propylene oxide: epoxy resin $=1: 1$ with microwave irradiation for 30-60 minutes. 


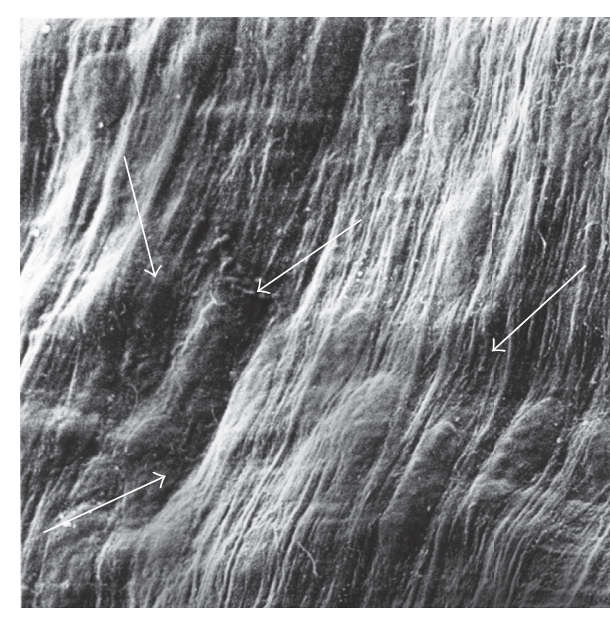

(a)

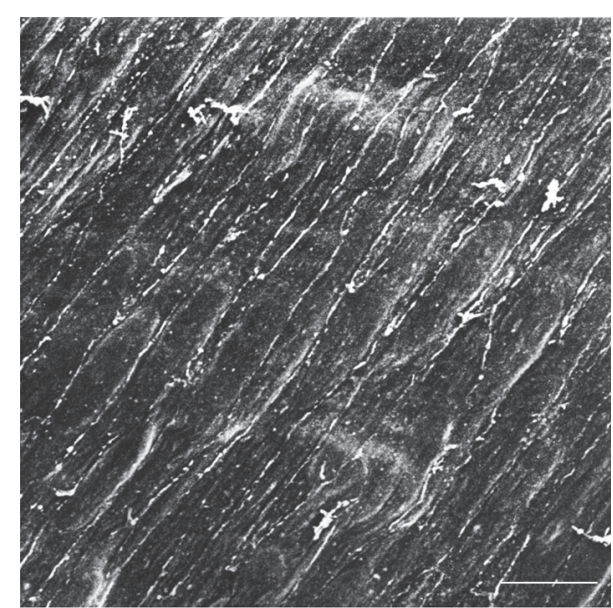

(b)

FIGURE 2: Scanning electron micrographs of venous endothelial cells without (a) or with (b) microwave irradiation. Guinea pig venous blood vessels were fixed conventionally with 1/2 Karnovsky's solution (a). Shrinkage of the smooth muscle cell layer occurred (a: arrows). After fixation with microwave irradiation, the flattened endothelial cell layer located in the inner surface of blood vessels was well-preserved (b). Arrows in (a) indicate the wavy artifacts caused by shrinkage of the smooth muscle cell layer. Compare (a) without microwave irradiation and (b) with microwave irradiation; the microwave irradiation showed good preservation of the endothelial cell layer morphology $(\mathrm{b})$. Bar = $10 \mu \mathrm{m}$. See also [55].

(8) Epoxy resin $100 \%$ and microwave irradiation for $30-$ 60 minutes.

(9) Embedding in epoxy resin according to standard procedures $\left(60^{\circ} \mathrm{C}\right)$ for $15-20$ hours, followed by thin sectioning.

Notes. For transmission electron microscopy, microwave irradiation also can reduce staining time with uranyl acetate and lead citrate $[24,58]$.

For Scanning Electron Microscopy [55]

(7) Transfer to $100 \% t$-butyl alcohol with microwave irradiation for 5 minutes $\times 2$ times.

(8) Samples are freeze-dried under high vacuum.

(9) Dehydrated samples are coated using an ionsputtering device (gold-platinum) and observed by scanning electron microscopy.

Samples with/without microwave treatment are shown in Figure 2.

9.3. Notes. Sample size should not exceed $2 \mathrm{~mm}$ (increase time for large-sized specimens $>2 \mathrm{~mm}$ in length). Do not exceed the maximum temperature of $50^{\circ} \mathrm{C}$. The exact time should be determined by each researcher. Do not exceed the maximum temperature of $50^{\circ} \mathrm{C}$ during the dehydration procedure using an alcohol series (50\%-100\%).

For postfixation in osmium tetroxide, sample temperature should not exceed $37^{\circ} \mathrm{C}$ when using microwave irradiation. To prevent exposure to osmium tetroxide gas, the procedure should be performed in a laboratory fume hood. Alternatively, postfixation can be performed conventionally for 1 hour at room temperature without microwave irradiation in a tightly closed screw-topped vial $(1 \mathrm{~mL}$ of $1 \%$ osmium tetroxide solution in $10-\mathrm{mL}$ vial).

\section{Application for Cryosectioning [42]}

Frozen sections are used for pathological diagnosis, enzyme detection, and immunofluorescent microscopy using antibodies. During freezing, crystallized water rapidly damages the tissues. Microwave irradiation reduces the formation of water crystals in tissues and can maintain the fine structure. Microwave irradiation mixes well with generally used TissueTek OCT compound (Sakura Finetek, Tokyo, Japan) and can be sliced very easily. Compared with nonirradiated specimens, microwave-irradiated samples have fewer bubbles around the tissues and structures are well-preserved.

Refer to Application for Tissue Fixation for tissue fixation protocol.

\subsection{Protocols}

(1) For cryoprotection, fixed tissues are immersed in 30\% sucrose solution with microwave irradiation until the sample sinks to the bottom of the beaker (all procedures in this protocol use intermittent irradiation, $5 \mathrm{~s}$ on $/ 5 \mathrm{~s}$ off at $200 \mathrm{~W}$ ). Change sucrose solution $2-3$ times to prevent reduction of sucrose concentration.

(2) Dissect samples into small blocks (5-10 $\mathrm{mm}$ ) using a sharp knife.

(3) Immerse trimmed tissues in $10 \mathrm{~mL}$ of TissueTek/sucrose solution $(1: 1)$ in a small beaker or plastic 
bottle with microwave irradiation for 10-15 minutes $(5 \mathrm{~s}$ on $/ 5 \mathrm{~s}$ off at $200 \mathrm{~W})$.

(4) Place the above tissues on parafilm (Bemis Flexible Packaging, Chicago, IL) and drop Tissue-Tek over the sample.

(5) [Optional] If bubbles are observed around the tissue, the sample could be treated with microwave irradiation for 5 minutes ( $5 \mathrm{~s}$ on $/ 5 \mathrm{~s}$ off at $200 \mathrm{~W}$ ), which can remove some bubbles.

(6) Place Tissue-Tek on precooled cryostat head, mount above sample, and drop Tissue-Tek over the samples as soon as possible.

(7) Quickly freeze Tissue-Tek and samples with HFC134a aerosol cold spray (CRYON: Oken-Syoji, Tokyo, Japan).

(8) Cut cryosections according to standard procedures.

Comments. When samples are mounted on the precooled cryostat head, freeze as quickly as possible to prevent formation of ice crystals in the samples.

\section{Application for Special Staining}

For special staining, such as that using periodic acidmethenamine-silver stain (PAM), Azan staining, Grimelius' method, Fontana-Masson stain, methenamine silver-nitrate Gomori-Grocott's variation, and Congo red stain, microwave irradiation allows good results without background staining within a very short time. Conventionally, the above staining procedures take 1-2 hours, while microwave irradiation allows completion of staining within $5-10$ minutes $[1,3,5,7$, $8,59]$.

\section{Conclusions}

Microwave irradiation can be applied during paraformaldehyde fixation and several types of staining procedure. It also significantly reduces the time required for staining procedures, such as immunohistochemistry, immunofluorescence microscopy, and special staining of tissues. Moreover, it reduces the time required for decalcification of bone. Conventional microwave ovens are unsuitable for laboratory use because the irradiation power is too high or they do not allow precise control of the power and sample temperature. Use of a conventional microwave oven requires calibration [60]. Modern microwave devices built specifically for laboratory use allow precise control over the power of microwave irradiation and sample temperature. Microwave irradiation should be highly applicable for many histological and cell biological techniques without any loss of morphology or immunoreactivity of tissues.

\section{Competing Interests}

The author declares that there is no conflict of interests regarding the publication of this paper.

\section{Acknowledgments}

The work reported here was supported by grants-in-aid for Promotional Projects for Advanced Education and Research, National University Corporation Tsukuba University of Technology.

\section{References}

[1] S. Valle, "Special stains in the microwave oven," Journal of Histotechnology, vol. 9, no. 4, pp. 237-239, 1986.

[2] M. E. Boon, L. P. Kok, H. E. Moorlag, P. O. Gerrits, and A. J. H. Suurmeijer, "Microwave-stimulated staining of plastic embedded bone marrow sections with the romanowsky-giemsa stain: improved staining patterns," Biotechnic and Histochemistry, vol. 62, no. 4, pp. 257-266, 1987.

[3] K. Matthews and J. K. Kelly, "A microwave oven method for the combined alcian blue-periodic acid-Schiff stain," Journal of Histotechnology, vol. 12, no. 4, pp. 295-297, 1989.

[4] A. S.-Y. Leong and P. Gilham, "A new, rapid, microwavestimulated method of staining melanocytic lesions," Stain Technology, vol. 64, no. 2, pp. 81-85, 1989.

[5] C. F. Danielson, T. Bloch, G. G. Brown, and D.-J. Summerlin, "The effect of microwave processing on histochemical staining reactions," Journal of Histotechnology, vol. 13, no. 3, pp. 181-183, 1990.

[6] J. Bonner and P. J. Armati, "Microwave assisted staining of nerve and muscle biopsy tissue," Biotechnic and Histochemistry, vol. 66, no. 5, pp. 236-238, 1991.

[7] H. J. G. van de Kant, M. E. Boon, and D. G. de Rooij, "Microwave applications before and during immunogold-silver staining," Journal of Histotechnology, vol. 16, no. 3, pp. 209-215, 1993.

[8] C. J. Churukian, "Microwave Giemsa technique for paraffin embedded tissue sections," Journal of Histotechnology, vol. 18, no. 4, pp. 319-322, 1995.

[9] C. Ilgaz, H. Kocabiyik, D. Erdogan, C. Özogul, and T. Peker, "Double staining of skeleton using microwave irradiation," Biotechnic \& Histochemistry, vol. 74, no. 2, pp. 57-63, 1999.

[10] Z. Kahveci, F. Z. Minday, and I. Cavusoglu, "Safranin O staining using a microwave oven," Biotechnic and Histochemistry, vol. 75, no. 6, pp. 264-268, 2000.

[11] S. G. Temel, S. Noyan, I. Cavusoglu, and Z. Kahveci, "A simple and rapid microwave-assisted hematoxylin and eosin staining method using 1,1,1 trichloroethane as a dewaxing and a clearing agent," Biotechnic and Histochemistry, vol. 80, no. 3-4, pp. 123132, 2005.

[12] B. Avci, N. Kahveci, Z. Kahveci, and S. A. Sirmali, "Using microwave irradiation in Marchi's method for demonstrating degenerated myelin," Biotechnic and Histochemistry, vol. 81, no. 2-3, pp. 63-69, 2006.

[13] Z. Kahveci, I. Çavuşoğlu, and Ş. A. Sirmali, "Microwave fixation of whole fetal specimens," Biotechnic and Histochemistry, vol. 72, no. 3, pp. 144-147, 1997.

[14] A. S.-Y. Leong and J. Milios, "Rapid immunoperoxidase staining of lymphocyte antigens using microwave irradiation," Journal of Pathology, vol. 148, no. 2, pp. 183-187, 1986.

[15] K. Y. Chiu and K. W. Chan, "Rapid immunofluorescence staining of human renal biopsy specimens using microwave irradiation," Journal of Clinical Pathology, vol. 40, no. 6, pp. 689-692, 1987. 
[16] J. Milios and A. S. Y. Leong, "The application of the avidinbiotin technique to previously stained histological sections," Stain Technology, vol. 62, no. 6, pp. 411-416, 1987.

[17] R. A. Moran, F. Nelson, J. Jagirdar, and F. Paronetto, "Application of microwave irradiation to immunohistochemistry: preservation of antigens of the extracellular matrix," Stain Technology, vol. 63, no. 5, pp. 263-269, 1988.

[18] P. A. Takes, J. Kohrs, R. Krug, and S. Kewley, "Microwave technology in immunohistochemistry: application to avidinbiotin staining of diverse antigens," Journal of Histotechnology, vol. 12, no. 2, pp. 95-98, 1989.

[19] M. Werner, R. von Wasielewski, and A. Georgii, "Immunodetection of a tumor associated antigen (TAG-12): comparison of microwave accelerated and conventional method," Biotechnic and Histochemistry, vol. 66, no. 2, pp. 79-81, 1991.

[20] L. van Vlijmen-Willems and P. van Erp, "Microwave irradiation for rapid and enhanced lmmunohistochemical staining: application to skin antigens," Biotechnic \& Histochemistry, vol. 68, no. 2, pp. 67-74, 1993.

[21] M. E. Boon and L. P. Kok, "Microwaves for immunohistochemistry," Micron, vol. 25, no. 2, pp. 151-170, 1994.

[22] A. S.-Y. Leong, "Microwaves in diagnostic immunohistochemistry," European Journal of Morphology, vol. 34, no. 5, pp. 381383, 1996.

[23] A. K. Katoh, N. Stemmler, S. Specht, and F. D’Amico, "Immunoperoxidase staining for estrogen and progesterone receptors in archival formalin fixed, paraffin embedded breast carcinomas after microwave antigen retrieval," Biotechnic and Histochemistry, vol. 72, no. 6, pp. 291-298, 1997.

[24] I. Cavusoglu, Z. Kahveci, and S. A. Sirmali, "Rapid staining of ultrathin sections with the use of a microwave oven," Journal of Microscopy, vol. 192, no. 2, pp. 212-216, 1998.

[25] S. Noyan, Z. Kahveci, I. Cavusoglu, F. Z. Minbay, F. B. Sunay, and S. A. Sirmali, "Effects of microwave irradiation and chemical fixation on the localization of perisinusoidal cells in rat liver by gold impregnation," Journal of Microscopy, vol. 197, no. 1, pp. 101$106,2000$.

[26] M. Kaneko, T. Tomita, T. Nakase et al., "Rapid decalcification using microwaves for in situ hybridization in skeletal tissues," Biotechnic \& Histochemistry, vol. 74, no. 1, pp. 49-54, 1999.

[27] E. M. Keithley, T. Truong, B. Chandronait, and P. B. Billings, "Immunohistochemistry and microwave decalcification of human temporal bones," Hearing Research, vol. 148, no. 1-2, pp. 192-196, 2000.

[28] I. N. Sheriffs, D. Rampling, and V. V. Smith, "Paraffin wax embedded muscle is suitable for the diagnosis of muscular dystrophy," Journal of Clinical Pathology, vol. 54, no. 7, pp. 517-520, 2001.

[29] F. Z. Minbay, Z. Kahveci, and I. Cavusoglu, "Rapid Bielschowsky silver impregnation method using microwave heating," Biotechnic \& Histochemistry, vol. 76, no. 5-6, pp. 233-237, 2001.

[30] T. Kumada, K. Tsuneyama, H. Hatta, S. Ishizawa, and Y. Takano, "Improved 1-h rapid immunostaining method using intermittent microwave irradiation: practicability on 5 years application in Toyama Medical and Pharmaceutical University Hospital," Modern Pathology, vol. 17, no. 9, pp. 1141-1149, 2004.

[31] S. G. Temel, F. Z. Minbay, Z. Kahveci, and L. Jennes, "Microwave-assisted antigen retrieval and incubation with cox2 antibody of archival paraffin-embedded human oligodendroglioma and astrocytomas," Journal of Neuroscience Methods, vol. 156, no. 1-2, pp. 154-160, 2006.
[32] H. Hatta, K. Tsuneyama, T. Kumada et al., "Freshly prepared immune complexes with intermittent microwave irradiation result in rapid and high-quality immunostaining," Pathology Research and Practice, vol. 202, no. 6, pp. 439-445, 2006.

[33] L. L. Emerson, S. R. Tripp, B. C. Baird, L. J. Layfield, and L. R. Rohr, "A comparison of immunohistochemical stain quality in conventional and rapid microwave processed tissues," American Journal of Clinical Pathology, vol. 125, no. 2, pp. 176-183, 2006.

[34] R. J. Buesa, "Microwave-assisted tissue processing: real impact on the histology workflow," Annals of Diagnostic Pathology, vol. 11, no. 3, pp. 206-211, 2007.

[35] D. J. Long II and C. Buggs, "Microwave oven-based technique for immunofluorescent staining of paraffin-embedded tissues," Journal of Molecular Histology, vol. 39, no. 1, pp. 1-4, 2008.

[36] C. C. Abreu, P. A. Nakayama, C. I. Nogueira et al., "Domestic microwave processing for rapid immunohistochemical diagnosis of bovine rabies," Histology and Histopathology, vol. 27, no. 9, pp. 1227-1230, 2012.

[37] S. Shi, Q. Cheng, P. Zhang et al., "Immunofluorescence with dual microwave retrieval of paraffin-embedded sections in the assessment of human renal biopsy specimens," American Journal of Clinical Pathology, vol. 139, no. 1, pp. 71-78, 2013.

[38] A. Bond and J. C. Kinnamon, "Microwave processing of gustatory tissues for immunohistochemistry," Journal of Neuroscience Methods, vol. 215, no. 1, pp. 132-138, 2013.

[39] Y. Kitayama, H. Igarashi, and H. Sugimura, "Initial intermittent microwave irradiation for fluorescence in situ hybridization analysis in paraffin-embedded tissue sections of gastrointestinal neoplasia," Laboratory Investigation, vol. 80, no. 5, pp. 779-781, 2000.

[40] Y. Kitayama, H. Igarashi, and H. Sugimura, "Different vulnerability among chromosomes to numerical instability in gastric carcinogenesis: stage-dependent analysis by FISH with the use of microwave irradiation," Clinical Cancer Research, vol. 6, no. 8, pp. 3139-3146, 2000.

[41] K. Kobayashi, Y. Kitayama, H. Igarashi et al., "Intratumor heterogeneity of centromere numerical abnormality in multiple primary gastric cancers: application of fluorescence in situ hybridization with intermittent microwave irradiation on paraffin-embedded tissue," Japanese Journal of Cancer Research, vol. 91, no. 11, pp. 1134-1141, 2000.

[42] K. Katoh, Y. Kano, and S. Ookawara, "Microwave irradiation for fixation and immunostaining of endothelial cells in situ," Biotechnic and Histochemistry, vol. 84, no. 3, pp. 101-108, 2009.

[43] K. Katoh, "Rapid fixation and immunofluorescent staining of cultured cells using microwave irradiation," Journal of Histotechnology, vol. 34, no. 1, pp. 29-34, 2011.

[44] G. Tornero, L. L. Latta, and G. Godoy, "Use of microwave radiation for the histological study of bone canaliculi," Journal of Histotechnology, vol. 14, no. 1, pp. 27-30, 1991.

[45] A. L. Marr and A. Wong, "Effects of microwave fixation and decalcification on rodent tissue," Journal of Histotechnology, vol. 32, no. 4, pp. 190-192, 2009.

[46] H. Utsunomiya, L. Shan, I. Kawano et al., "Immunolocalization of parathyroid hormone in human parathyroid glands with special references to microwave antigen retrieval," Endocrine Pathology, vol. 6, no. 3, pp. 223-227, 1995.

[47] R. W. M. Hoetelmans, H.-J. van Slooten, R. Keijzer, C. J. H. van de Velde, and J. H. van Dierendonck, "Comparison of the effects of microwave heating and high pressure cooking for antigen retrieval of human and rat Bcl-2 protein in formaldehyde-fixed, 
paraffin-embedded sections," Biotechnic \& Histochemistry, vol. 77, no. 3, pp. 137-144, 2002.

[48] Z. Kahveci, F. Z. Minbay, S. Noyan, and I. Çavusoglu, "A comparison of microwave heating and proteolytic pretreatment antigen retrieval techniques in formalin fixed, paraffin embedded tissues," Biotechnic and Histochemistry, vol. 78, no. 2, pp. 119-128, 2003.

[49] L. Gu, J. Cong, J. Zhang, Y. Tian, and X. Zhai, "A microwave antigen retrieval method using two heating steps for enhanced immunostaining on aldehyde-fixed paraffin-embedded tissue sections," Histochemistry and Cell Biology, vol. 145, no. 6, pp. 675-680, 2016.

[50] Y. Kano, K. Katoh, and K. Fujiwara, "Lateral zone of cell-cell adhesion as the major fluid shear stress-related signal transduction site," Circulation Research, vol. 86, no. 4, pp. 425-433, 2000.

[51] R. D. Krug and P. A. Takes, "Microwave technology in immunohistochemistry: II. A universal staining protocol using diaminobenzidine as the chromogen," Journal of Histotechnology, vol. 14, no. 1, pp. 31-34, 1991.

[52] R. A. Shiurba, E. T. Spooner, K. Ishiguro et al., "Immunocytochemistry of formalin-fixed human brain tissues: microwave irradiation of free-floating sections," Brain Research Protocols, vol. 2, no. 2, pp. 109-119, 1998.

[53] T. Kumada, K. Tsuneyama, H. Hatta, S. Ishizawa, and Y. Takano, "Improved 1-h rapid immunostaining method using intermittent microwave irradiation: practicability based on 5 years application in Toyama Medical and Pharmaceutical University Hospital," Modern Pathology, vol. 17, no. 9, pp. 1141-1149, 2004.

[54] K. Katoh and Y. Noda, "Distribution of cytoskeletal components in endothelial cells in the guinea pig renal artery," International Journal of Cell Biology, vol. 2012, Article ID 439349, 10 pages, 2012.

[55] K. Katoh, Y. Kano, and S. Ookawara, "Morphological differences between guinea pig aortic and venous endothelial cells in situ," Cell Biology International, vol. 31, no. 6, pp. 554-564, 2007.

[56] A. S.-Y. Leong and R. T. Sormunen, "Microwave procedures for electron microscopy and resin- embedded sections," Micron, vol. 29, no. 5, pp. 397-409, 1998.

[57] P. Webster, "Microwave-assisted processing and embedding for transmission electron microscopy," Methods in Molecular Biology, vol. 1117, pp. 21-37, 2014.

[58] F. Hernandez-Chavarria and M. Vargas-Montero, "Rapid contrasting of ultrathin sections using microwave irradiation with heat dissipation," Journal of Microscopy, vol. 203, no. 2, pp. 227230, 2001.

[59] N. T. Brinn, "Rapid metallic histological staining using the microwave oven," Journal of Histotechnology, vol. 6, no. 3, pp. 125-129, 1983.

[60] R. J. Buesa, "Haven't you calibrated your microwave oven yet?" Journal of Histotechnology, vol. 25, no. 1, pp. 39-43, 2002. 

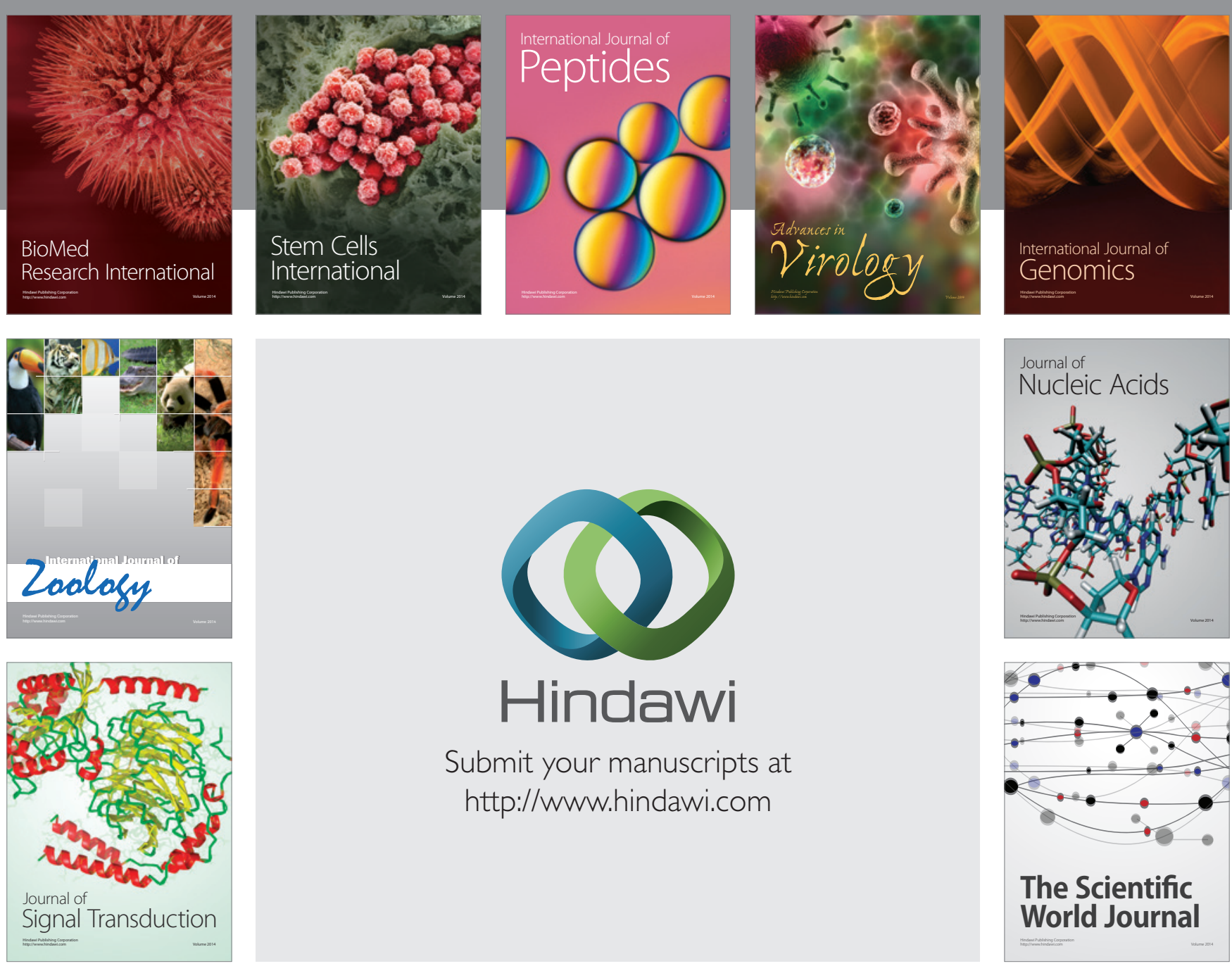

Submit your manuscripts at

http://www.hindawi.com
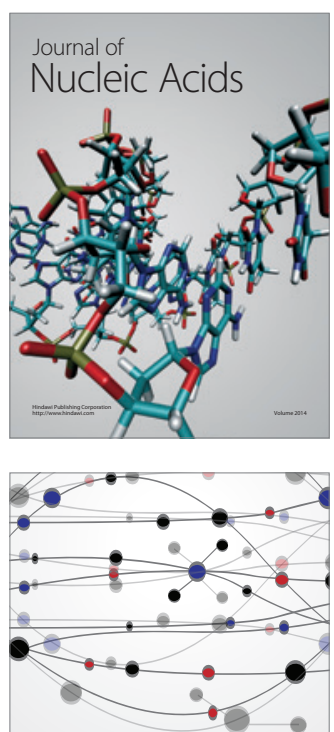

The Scientific World Journal
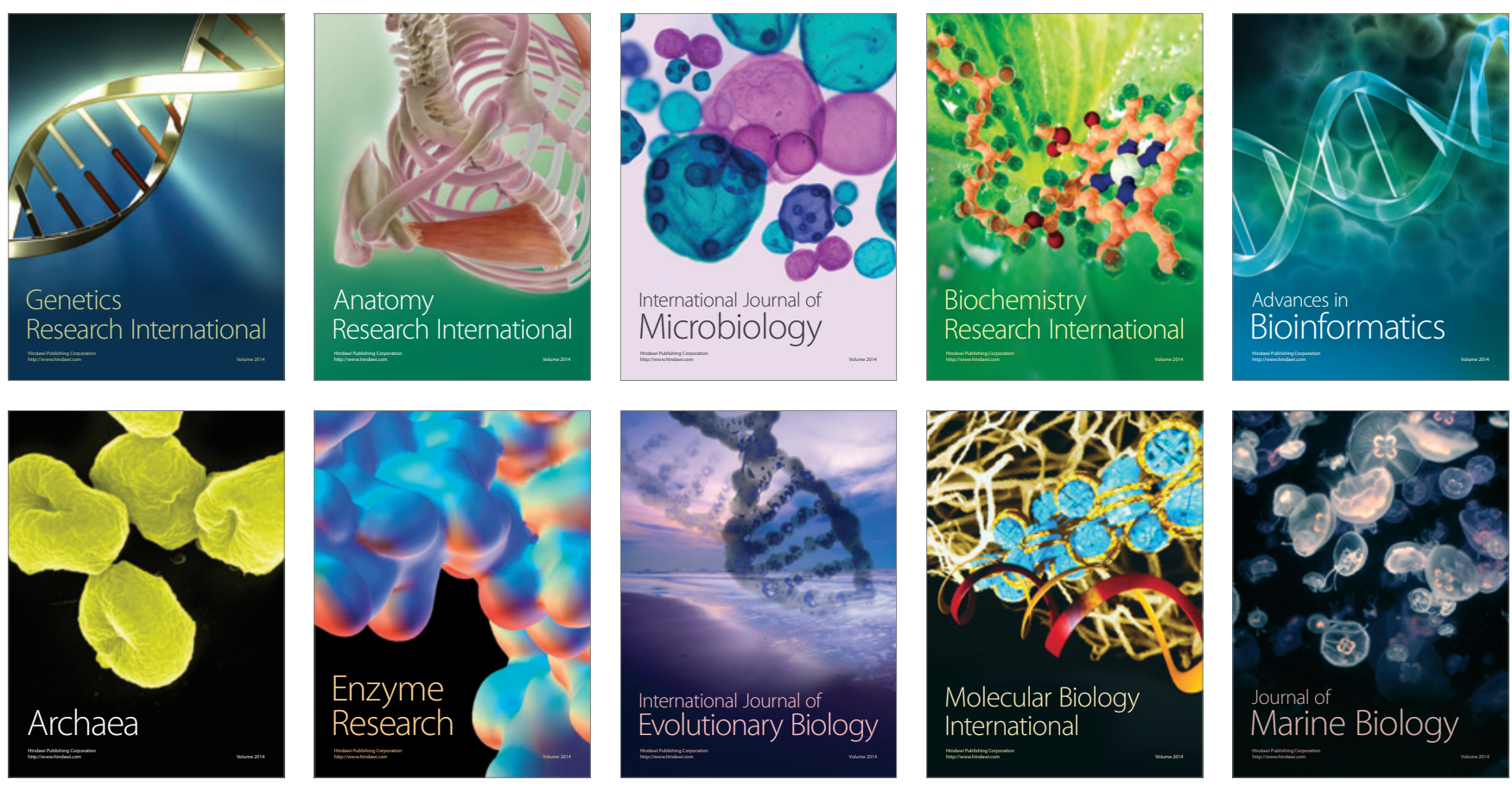